\title{
Influence of Temperature and Salt on Association and Thermodynamic Parameters of Micellization of a Cationic Gemini Surfactant
}

\author{
Sanjeev Kumar* and Kushan Parikh
}

\author{
Soft Material Research Lab, Department of Chemistry, Faculty of Science, The Maharaja Sayajirao University \\ of Baroda, Vadodara - 390 002, India
}

\begin{abstract}
Association behavior of a gemini surfactant, N,N'-(ethane-1,2-diylbis(oxy))bis(2-oxoethane-2,1-diyl))bis(N,Ndimethylhexadecan-1-aminium) chloride, has been studied conductometrically at different temperatures (293.15 to $338.15 \mathrm{~K}$ ) in aqueous and aqueous ethylene glycol solvents. The association studies were also performed in aqueous salt solution (sodium chloride, $\mathrm{NaCl}$ or sodium salicylate, $\mathrm{NaSal}$ ). Critical micelle concentration (cmc) decreases and then increases with continuous increase in temperature ( $\mathrm{U}$-shaped behavior). The temperature $\left(T_{\mathrm{m}}\right)$ corresponds to lowest $\mathrm{cmc}\left(\mathrm{cmc}_{\mathrm{m}}\right)$ has been found $\approx 325 \mathrm{~K}$ for both the solvents (water and water + ethylene glycol). However, $\mathrm{cmc}$ increases in mixed solvent (water + ethylene glycol). The $T_{\mathrm{m}}$ has been shifted to lower temperature in the presence of salt. The shifting in $T_{\mathrm{m}}$ was dependent upon the nature of the counter ion. The $\mathrm{cmc}-$ temperature variation can be represented by a power law relationship. Relevant thermodynamic parameters have been evaluated and discussed on the basis of the nature of the solvent / counter ion. The enthalpy - entropy compensation plots exhibit linearity. The compensation temperature $\left(T_{\mathrm{c}}\right)$ and enthalpy change $\left(\Delta H_{\text {mic }}\right.$ ) have been computed for various surfactant - solvent systems.
\end{abstract}

Keywords: Gemini surfactant, micellization, conductometry, thermodynamics, enthalpy - entropy compensation.

\section{INTRODUCTION}

During the past few decades, association structures produced by a self-assembly processing have received considerable attention due to their dynamic nature [1]. For the purpose, various surfactants have been synthesized to explore water soluble supramolecular structures. Depending on the experimental conditions, molecular structure and shape, and relative volume fraction of hydrophilic and hydrophobic parts, the surfactant molecules self-assemble into various supramolecular structures e.g., spherical or cylindrical micelles. The molecular self-assembly of the surfactants is ideally suitable for the construction of the responsive material since the dynamic and reversible conformational changes can be triggered by external environment. The concentration at which the formation of surfactant micelle takes place is termed as critical micelle concentration (cmc). Inclusion of different types of additive is well-known to influence the micellar properties (e.g., cmc) of the surfactant solution by affecting the solvent structure or micellar morphology [2-5]. cmc is the first and foremost property to be known for all the surfactants before their use for any kind of application.

Dimeric or gemini surfactants are composed of two hydrophilic heads and two alkyl tails covalently linked

*Address corresponding to this author at the Soft Material Research Lab, Department of Chemistry, Faculty of Science, The Maharaja Sayajirao University of Baroda, Vadodara - 390 002, India; Tel: +91-265-2795552; Fax:+91-265-2792277; E-mail: drksanjeev@gmail.com through a spacer. These surfactants attracted attention both from industry and academic fields. They have shown superior solution properties in comparison with conventional surfactants e.g., very low $\mathrm{cmc}$, more efficient in decreasing the surface tension of water, superior wetting properties, etc. [6-8]. Further, a few gemini surfactants have also shown interesting antimicrobial or antibacterial activities [9].

It is well documented that the cmc of surfactant varies with temperature. The variation of $\mathrm{cmc}$ with temperature observed for ionic surfactants is much different than their non-ionic counterparts. Generally, $\mathrm{cmc}$ of non-ionic surfactants decreases regularly with increase in temperature (till critical solution temperature). However, ionic surfactants show a more interesting behavior: $\mathrm{cmc}$ decreases to a certain value $\left(\mathrm{cmc}_{\mathrm{m}}\right)$ and then increases with continuous increase in temperature (U-shaped behavior) [10-14]. The temperature at $c m c_{m}\left(T_{m}\right)$ for both non-ionic and ionic surfactants increases as the hydrophobicity of the surfactant decreases. However, $T_{\mathrm{m}}$ was always higher for non-ionic surfactants than for ionic ones $[5,11]$. The temperature $-\mathrm{cmc}$ relationship can be represented by a power law $[10,15]$. The temperature effect on the $\mathrm{cmc}$ can also use to obtain various thermodynamic energetics of micellization. Further, the micellization process has been reported to exhibit an enthalpy entropy compensation [16].

Recently, the temperature effect on micellization of gemini surfactants has been studied much [2,5,17-29]. 
However, only a few studies reported a minimum in the $\mathrm{cmc} v s$ temperature plot in aqueous medium for gemini surfactants $[20,29]$. Similarly, no serious attempt has been made to study enthalpy - entropy compensation in gemini surfactant micellization process. Spacer has remarkable effect on the micellization properties of the surfactant. For hydrophilic spacer, the $\mathrm{cmc}$ increases with progressive increase in spacer chain length [30]. However, the cmc passes through a broad maximum with increasing the spacer length of a hydrophobic spacer [31].

In the present study, we have synthesized a gemini surfactant (N,N'-((ethane-1,2-diyl bis(oxy)) bis (2oxoethane-2,1-diyl)) bis ( $\mathrm{N}, \mathrm{N}$-dimethylhexadecan-1aminium) chloride) having a biodegradable spacer [32] and performed a study of temperature effect on the $\mathrm{cmc}$ under variety of solvent conditions (aqueous, aqueous + ethylene glycol mixed solvent, mass fraction $(\phi=0.11)$, and in aqueous salt (sodium chloride, $\mathrm{NaCl}$ or sodium salicylate, NaSal, mole fractions $(x)=0.95$ or 0.33 , respectively)). The effect of temperature on $\mathrm{cmc}$ follows a power law. Thermodynamic parameters have been calculated by the temperature dependence of cmc.

\section{EXPERIMENTAL SECTION}

\section{Materials}

Chloroacetylchloride (98\%, S.d.Fine Chemicals, used after simple distillation), ethylene glycol, EG (99\%, Sigma Aldrich), N, N-hexadecyl dimethylamine (95\%, Sigma Aldrich), sodium chloride, $\mathrm{NaCl}$ (99\%, Merck) and sodium salicylate, NaSal (99\%, Merck) were used as received. However, the salts were dried in a vacuum oven $(3-4 \mathrm{~h})$ before use. For preparation of the sample solution, water was demineralised in $\mathrm{KMnO}_{4}$ solution and double distilled in all glass assembly. The specific conductivity of distilled water was $1-2 \mu \mathrm{S} / \mathrm{cm}$.

\section{Synthesis of Gemini Surfactant with Biodegradable Spacer}

The cationic gemini surfactant as shown in Scheme 1 was synthesized in two steps. Spacer, 1, 2 - bischloroacetoxy-ethane, was synthesized by drop by drop addition of chloro acetyl chloride in ethylene glycol followed by refluxing for 8 hrs as reported in the literature [33]. In the second step, 1, 2 - bischloroacetoxy-ethane and N, N-Hexadecyl dimethylamine was refluxed in dry ethyl acetate for 24 $\mathrm{h}$. The solvent was removed under vacuum and a white solid mass was obtained. This solid mass recrystallized at least $3-4$ times in ethyl acetate: DCM (8:2) mixture. The obtained white shiny powder was dried in a vacuum oven for several hours. The synthesized surfactant is named as gemini and used throughout in the manuscript.

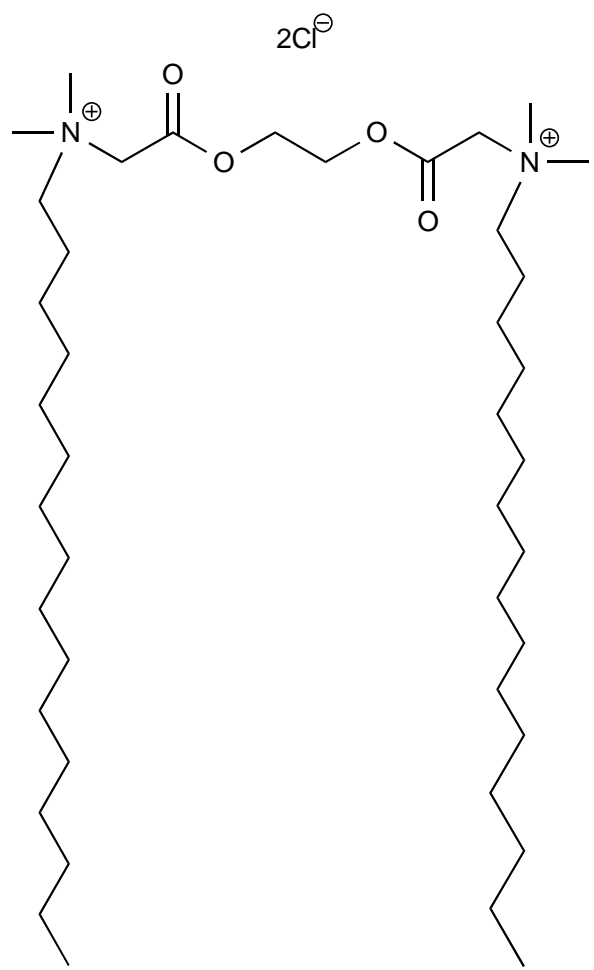

Scheme 1: Structure of N,N'-((ethane-1,2-diylbis(oxy))bis(2oxoethane-2,1-diyl))bis(N,N dimethylhexadecan-1-aminium) chloride as Gemini Surfactant.

\section{Spectral Characteristics of Gemini Surfactant}

The purity of the synthesized gemini was checked by ${ }^{1} \mathrm{H}$ NMR (Bruker, $400 \mathrm{MHz}$ ), FT-IR (8400S Shimadzu), elemental analysis and surface tensiometry. ${ }^{1} \mathrm{H}$ NMR $\left(400 \mathrm{MHz}, \mathrm{CDCl}_{3}\right) \delta 0.867 \quad$ $0.900(\mathrm{t}, 6 \mathrm{H}), \delta 1.256-1.349(\mathrm{t}, 52 \mathrm{H}), \delta 1.781(\mathrm{~s}, 4 \mathrm{H})$, $\delta 3.555(\mathrm{~s}, 12 \mathrm{H}), \delta 3.795-3.837(\mathrm{t}, 4 \mathrm{H}), \delta 4.487(\mathrm{~s}$, $4 \mathrm{H}), \delta 5.111(\mathrm{~s}, 4 \mathrm{H}) . \mathrm{CHN}$ Analysis, Anal. Calculated for $\mathrm{C}_{42} \mathrm{H}_{86} \mathrm{~N}_{2} \mathrm{O}_{4} \mathrm{Cl}_{2}$ (\%) : C 66.90, H 11.50, N 3.72 . Found C 65.63, H 11.87, N 3.12. FT-IR $\left(\mathrm{KBr}, \mathrm{cm}^{-1}\right)$ : 2920, 2853, 1751, 1636, 1472, 1187, 1048. The spectroscopic data were found in good agreement with the literature value reported earlier [34].

\section{Conductivity Measurements}

Conductometric measurements were carried out by using a conductivity meter EUTECH cyberscan CON510 (cell constant $1 \mathrm{~cm}^{-1}$ ) with an inbuilt 
temperature sensor. A pre-calibrated conductivity cell was used to obtain a specific conductance at an appropriate concentration range. The temperature of the sample solution was precisely controlled by SCHOTT CT1650 thermostat with an accuracy of \pm $0.01{ }^{\circ} \mathrm{C}$. The cell with the appropriate amount of the solvent in a vessel was placed in a thermostat for at least 30 minutes prior to the measurement.

\section{RESULTS AND DISCUSSION}

\section{Determination of cmc, $T_{\mathrm{m}}$ and Power Law Exponents}

The $\mathrm{cmc}$ and degree of dissociation $(\alpha)$ values for the gemini surfactant were determined from the intersection and the ratio of the slopes, respectively, of two straight lines in the plot of the specific conductance (к) vs [surfactant] as reported earlier [3]. Figure 1 shows the dependence of the $\mathrm{cmc}$ on temperature for pure water, water $+E G$ mixed solvent system, $\phi_{E G}=$ 0.11 , aqueous $\mathrm{NaCl}$ and aqueous $\mathrm{NaSal}, x_{\mathrm{NaCl}}=0.95$ and $x_{\text {NaSal }}=0.33$, respectively. The $\mathrm{cmc}$ data are given in Tables 1 and 2. $\alpha$ has shown weak dependence on temperature and hence an average value $\left(\alpha_{\mathrm{a}}\right)$ was used for whole temperature range and included in Tables 1 and 2. It was observed that $\mathrm{cmc}$ decreases with temperature to a certain value $\left(\mathrm{cmc}_{\mathrm{m}}\right)$ followed by an increase. The initial heating causes the decrease in hydration of the hydrophilic head group which favors micellization. Probably, this may be the reason for the decrease in the cmc (Figure 1). However, when the surfactant molecules dissolve in aqueous medium the alkyl tail group distorts the water structure. Raising the

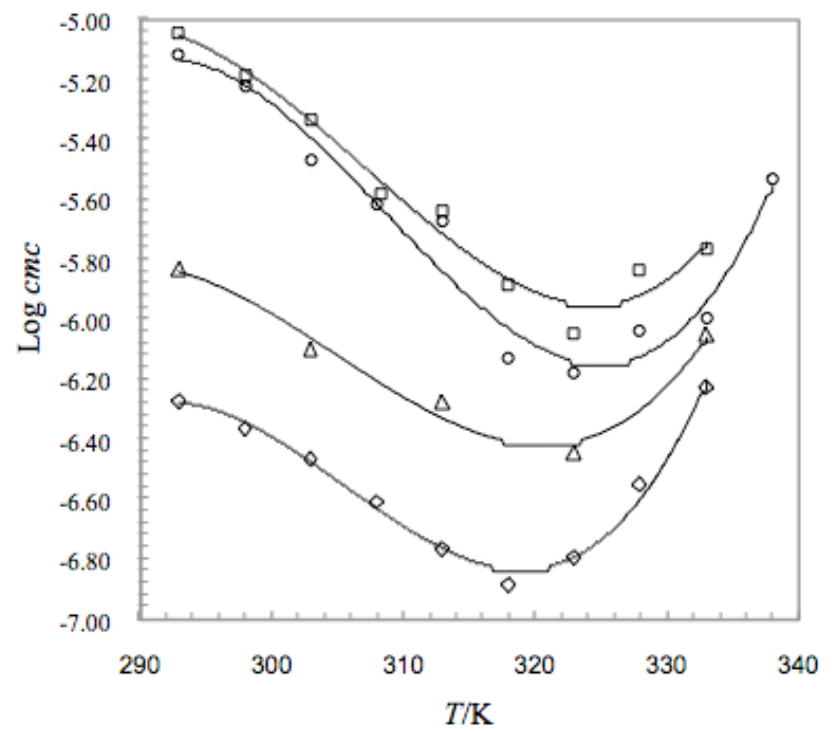

Figure 1: cmc vs Temperature for Gemini Surfactant in; $\circ$, Pure Water; $\square, \phi_{\mathrm{EG}}=0.11 ; \Delta, x_{\mathrm{NaCl}}=0.95 ; \diamond, x_{\mathrm{NaSal}}=0.33$. temperature also causes breakdown of structured water around the alkyl tail part which opposes the micellization. Above two factors, (i) decrease in head group hydration and (ii) break down of structured water around tail part, compete for the resulting effect on micellization phenomenon and the $\mathrm{cmc}$ value. The $\mathrm{cmc}$ increase in the latter part may be due to the predominance of second factor as indeed observed in Figure 1. Generally, $T_{\mathrm{m}}$ was reported between $273 \mathrm{~K}$ to $313 \mathrm{~K}$ for ionic surfactants [10] and $\approx 323 \mathrm{~K}$ for many non-ionic surfactants [35]. It is intriguing to note, though the present gemini is (cat) ionic in nature but $T_{\mathrm{m}}$ was found $\approx 326 \mathrm{~K}$ (Table 3 ) which is generally observed for non-ionic ones. This may be due to the hydration of the spacer which contains oxygen atoms of the carboxylate unit in addition to the usual hydration of the head group. This indicates that the head group hydration predominate the micellization process and even counteract the second factor up to a distinctly higher temperature.

The addition of a polar organic solvent to water is expected to change the physical properties (dielectric constant $(\varepsilon)$ and dipole moment) [36]. The presence of $E G$ in the solvent mixture can decrease the $\varepsilon$ than of pure water $\left(\varepsilon_{\text {water }}=78.5\right.$ and $\varepsilon_{\mathrm{EG}}=37.7$ at $\left.293 \mathrm{~K}\right)$. An overall $\mathrm{cmc}$ increase was observed in $0.11 \phi_{\mathrm{EG}}$ (at different temperature) without affecting $T_{\mathrm{m}}$ much. The addition of polar organic solvents may decrease the hydrophobic interaction between alkyl groups of the surfactant (diminishing of factor - ii). Additionally, when the $\varepsilon$ value of the solvent decreases, the repulsion between the head groups increases and thus $\mathrm{cmc}$ value increases (Table 1).

The addition of salt to the aqueous solution, at a given temperature, causes a decrease in $\mathrm{cmc}$ (Figure 2 and Table 2). It may be due to screening of the repulsion between cationic head groups of the surfactant in the presence of counter ions ( $\mathrm{Cl}^{-}$or Sal $)$ which facilitate early formation of the micelles. This indeed was observed in the present study and confirms the earlier reports $[16,37]$. However, a distinct fall in $T_{\mathrm{m}}$ values was observed in the presence of salts (Table 3 ). The decrease was more pronounced with the salt containing hydrophobic counterion (Sal ${ }^{-}$. It has been reported earlier that hydrophobicity of the counterion plays an important role in the aggregation process [38]. Sal is known for a strong binding with the cationic head groups and for screening the repulsive coulombic interactions. The presence of salt and increase of temperature may cause decrease in hydration of the hydrophilic group synergistically and therefore first 
Table 1: Various Micellization (cmc and $\left.\alpha_{a}\right)$ and Thermodynamic Parameters $\left(\Delta G_{\text {mic }}^{\circ}, \Delta H_{\text {mic }}^{\circ}\right.$ and $\left.\Delta S_{\text {mic }}^{\circ}\right)$ of $G e m i n i$ Surfactant in Water + Ethylene Glycol Mixed Media at Different Temperatures

\begin{tabular}{|c|c|c|c|c|c|c|}
\hline \multirow{2}{*}{$\phi_{\mathrm{EG}}$} & $T$ & cmc $\cdot 10^{5}$ & \multirow{2}{*}{$\alpha_{a}$} & $\Delta G_{\text {mic }}^{\circ}$ & $\Delta H_{\text {mic }}^{\circ}$ & $\Delta S_{\text {mic }}^{\circ}$ \\
\hline & K & $\mathrm{mol} \cdot \mathrm{kg}^{-1}$ & & $\mathrm{~kJ} \cdot \mathrm{mol}^{-1}$ & $\mathrm{~kJ} \cdot \mathrm{mol}^{-1}$ & $\mathrm{~kJ} \cdot \mathrm{K}^{-1} \cdot \mathrm{mol}^{-1}$ \\
\hline \multirow[t]{8}{*}{0.00} & 293.15 & $0.760 \pm 0.02$ & \multirow{8}{*}{$0.72 \pm 0.02$} & $-57.03 \pm 0.07$ & $11.65 \pm 0.19$ & $0.23 \pm 0.001$ \\
\hline & 298.15 & $0.600 \pm 0.04$ & & $-62.03 \pm 0.23$ & $73.45 \pm 0.20$ & $0.45 \pm 0.002$ \\
\hline & 303.15 & $0.340 \pm 0.03$ & & $-53.58 \pm 0.28$ & $94.15 \pm 0.17$ & $0.49 \pm 0.002$ \\
\hline & 308.15 & $0.240 \pm 0.01$ & & $-72.99 \pm 0.20$ & $144.14 \pm 0.23$ & $0.70 \pm 0.001$ \\
\hline & 318.15 & $0.073 \pm 0.004$ & & $-85.44 \pm 0.21$ & $109.45 \pm 0.25$ & $0.61 \pm 0.001$ \\
\hline & 323.15 & $0.065 \pm 0.003$ & & $-69.68 \pm 0.18$ & $30.88 \pm 0.20$ & $0.31 \pm 0.001$ \\
\hline & 328.15 & $0.090 \pm 0.004$ & & $-78.55 \pm 0.19$ & $-61.75 \pm 0.23$ & $0.05 \pm 0.001$ \\
\hline & 333.15 & $0.100 \pm 0.005$ & & $-90.88 \pm 0.25$ & $-223.13 \pm 0.27$ & $-0.40 \pm 0.002$ \\
\hline \multirow{8}{*}{0.11} & 298.15 & $0.650 \pm 0.03$ & \multirow{8}{*}{$0.80 \pm 0.03$} & $-45.69 \pm 0.12$ & $56.47 \pm 0.16$ & $0.34 \pm 0.001$ \\
\hline & 303.15 & $0.460 \pm 0.02$ & & $-51.56 \pm 0.15$ & $81.83 \pm 0.18$ & $0.44 \pm 0.001$ \\
\hline & 308.45 & $0.260 \pm 0.02$ & & $-61.20 \pm 0.18$ & $99.56 \pm 0.21$ & $0.52 \pm 0.001$ \\
\hline & 313.15 & $0.230 \pm 0.01$ & & $-52.89 \pm 0.15$ & $75.86 \pm 0.18$ & $0.41 \pm 0.001$ \\
\hline & 318.15 & $0.130 \pm 0.01$ & & $-51.85 \pm 0.14$ & $48.03 \pm 0.17$ & $0.31 \pm 0.001$ \\
\hline & 323.15 & $0.090 \pm 0.01$ & & $-75.85 \pm 0.21$ & $12.53 \pm 0.24$ & $0.27 \pm 0.001$ \\
\hline & 328.15 & $0.145 \pm 0.01$ & & $-63.58 \pm 0.16$ & $-57.49 \pm 0.21$ & $0.02 \pm 0.001$ \\
\hline & 333.15 & $0.170 \pm 0.01$ & & $-62.05 \pm 0.18$ & $-144.22 \pm 0.21$ & $-0.25 \pm 0.001$ \\
\hline
\end{tabular}

Table 2: Various Micellization ( $c m c$ and $\alpha_{\mathrm{a}}$ ) and Thermodynamic Parameters $\left(\Delta G_{\text {mic }}^{\circ}, \Delta H_{\text {mic }}^{\circ}\right.$ and $\Delta S_{\text {mic }}^{\circ}$ of $G_{e m i n i}$ Surfactant with Different Salt Mole Fraction $(x)$ in Water at Different Temperatures

\begin{tabular}{|c|c|c|c|c|c|c|c|}
\hline \multirow{2}{*}{ Salt } & \multirow{2}{*}{$x$} & $T$ & $c m c \cdot 10^{6}$ & \multirow{2}{*}{$\alpha_{a}$} & $\Delta G_{\text {mic }}^{\circ}$ & $\Delta H_{\text {mic }}^{\circ}$ & $\Delta S_{\text {mic }}^{\circ}$ \\
\hline & & K & $\mathrm{mol} \cdot \mathrm{kg}^{-1}$ & & $\mathrm{~kJ} \cdot \mathrm{mol}^{-1}$ & $\mathrm{~kJ} \cdot \mathrm{mol}^{-1}$ & $\mathrm{~kJ} \cdot \mathrm{K}^{-1} \cdot \mathrm{mol}^{-1}$ \\
\hline \multirow[t]{4}{*}{$\mathrm{NaCl}$} & \multirow[t]{4}{*}{0.95} & 293.15 & $1.46 \pm 0.07$ & \multirow{4}{*}{$0.78 \pm 0.02$} & $-51.90 \pm 0.12$ & $26.69 \pm 0.23$ & $0.27 \pm 0.001$ \\
\hline & & 303.15 & $0.79 \pm 0.04$ & & $-63.76 \pm 0.15$ & $70.20 \pm 0.27$ & $0.44 \pm 0.001$ \\
\hline & & 313.15 & $0.53 \pm 0.03$ & & $-71.16 \pm 0.17$ & $57.48 \pm 0.29$ & $0.41 \pm 0.002$ \\
\hline & & 323.15 & $0.36 \pm 0.02$ & & $-70.92 \pm 0.16$ & $-28.40 \pm 0.29$ & $0.13 \pm 0.001$ \\
\hline \multirow[t]{6}{*}{$\mathrm{NaSal}$} & \multirow[t]{6}{*}{0.33} & 293.15 & $0.53 \pm 0.03$ & \multirow[t]{6}{*}{$0.59 \pm 0.02$} & $-72.02 \pm 0.18$ & $12.44 \pm 0.11$ & $0.29 \pm 0.001$ \\
\hline & & 298.15 & $0.43 \pm 0.02$ & & $-68.52 \pm 0.17$ & $55.97 \pm 0.10$ & $0.42 \pm 0.001$ \\
\hline & & 303.15 & $0.34 \pm 0.02$ & & $-94.38 \pm 0.23$ & $107.62 \pm 0.14$ & $0.67 \pm 0.001$ \\
\hline & & 308.15 & $0.25 \pm 0.01$ & & $-118.30 \pm 0.29$ & $134.17 \pm 0.17$ & $0.82 \pm 0.002$ \\
\hline & & 328.15 & $0.28 \pm 0.02$ & & $-74.02 \pm 0.19$ & $-169.77 \pm 0.11$ & $-0.29 \pm 0.001$ \\
\hline & & 333.15 & $0.59 \pm 0.03$ & & $-66.11 \pm 0.17$ & $-282.37 \pm 0.10$ & $-0.65 \pm 0.001$ \\
\hline
\end{tabular}


factor predominates much at lower temperature [11]. However, in the presence of salt above factor influences only up to a lower temperature because hydration is partially taken care by countering binding. Beyond this, break down of the structure of water around the alkyl tail (vide supra) starts predominating the micellization process and responsible for the lower $T_{\mathrm{m}}$. The data in Table 3 are in consonance with this fact.

Table 3: Temperature of Minimum $\mathrm{cmc}\left(T_{\mathrm{m}}\right)$ and $\mathrm{cmc}$ at Minimum $\left(\mathrm{cmc}_{\mathrm{m}}\right)$ of Gemini Surfactant in Different System

\begin{tabular}{|c|c|c|}
\hline \multirow{2}{*}{ Gemini } & $\boldsymbol{T}_{\mathbf{m}}$ & $\mathbf{c m c}_{\mathbf{m}} \cdot \mathbf{1 0}^{\mathbf{5}}$ \\
\cline { 2 - 3 } & $\mathbf{K}$ & $\mathbf{m o l} \cdot \mathbf{k g}^{-1}$ \\
\hline \hline Pure water & $326.0 \pm 0.7$ & $0.065 \pm 0.003$ \\
\hline$\phi_{\mathrm{EG}}=0.11$ & $325.0 \pm 0.5$ & $0.090 \pm 0.005$ \\
\hline $\mathrm{X}_{\mathrm{NaCl}}=0.95$ & $321.0 \pm 0.4$ & $0.036 \pm 0.002$ \\
\hline $\mathrm{X}_{\mathrm{NaSal}}=0.33$ & $318.5 \pm 0.5$ & $0.013 \pm 0.001$ \\
\hline
\end{tabular}

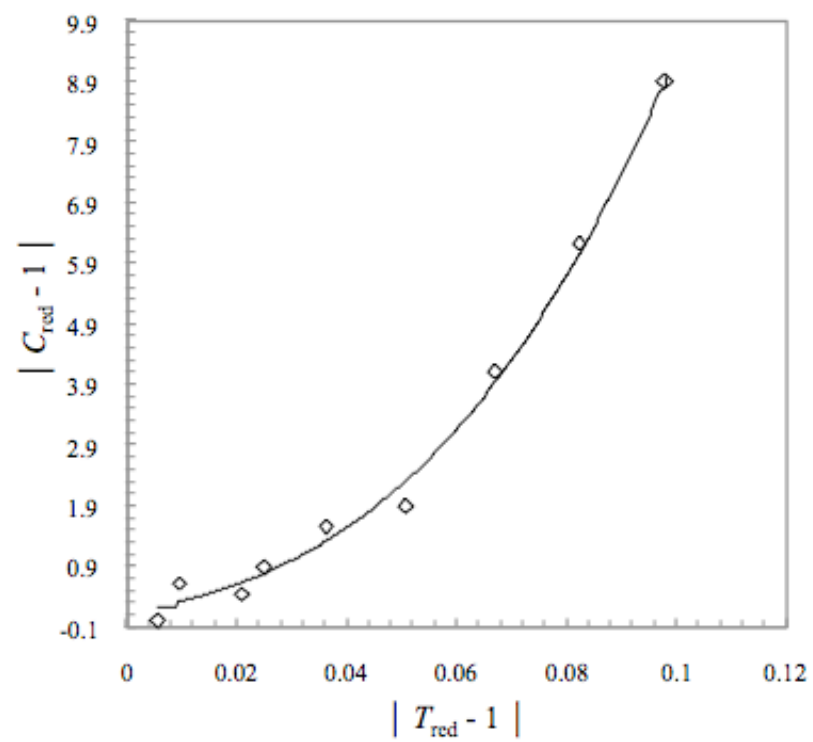

Figure 2: Reduced Variable Fit of $\mathrm{cmc}$ Data for the Gemini Surfactant in $\phi_{\mathrm{EG}}=0.11$.

Temperature dependence of $\mathrm{cmc}$ can be fitted by a power law between reduced variables; where reduced variables are $C_{\text {red }}=C_{\mathrm{cmc}} / \mathrm{cm} c_{\mathrm{m}}$ and $T_{\text {red }}=T / T_{\mathrm{m}}$. $T_{\text {red }}$ and $C_{\text {red }}$ are related to each other by the relation;

$\left(C_{\text {red }}-1\right)=\mathrm{A}\left(T_{\text {red }}-1\right)^{\gamma}$

Where, $\mathrm{A}$ is the constant and $\gamma$ is an exponent representing the nature of the surfactant system. Table 4 summarizes the results of the fitting of eq 1 from the $\mathrm{cmc}$ data of Tables $\mathbf{1}$ and $\mathbf{2}$. The accuracy of the fit can be seen from the observance of experimental data on the representative curve (Figure 2) shown for $0.11 \phi_{\mathrm{EG}}$ (not shown for others). The Data in Table 4 indicate that the nature of the solvent has a significant effect on the value of $A$ and $\gamma$ though the same surfactant was used each time. The value of $\gamma$ was derived from a logarithmic regression fit [10] and seems to be dependent on the nature of the additive. The data is not sufficient to comment more about the solvent effect (or additive effect) on fitting parameters ( $\gamma$ and $A$ ). Different values of $\gamma$ were reported for various surfactant systems $[15,39]$.

Table 4: Exponent $(\gamma)$ and Constant (A) of Gemini Surfactant in Different System

\begin{tabular}{|c|c|c|}
\hline Gemini & $\gamma$ & A \\
\hline \hline Pure water & $3.19 \pm 0.08$ & $14.15 \pm 0.32$ \\
\hline$\phi_{\mathrm{EG}}=0.11$ & $2.55 \pm 0.12$ & $11.57 \pm 0.46$ \\
\hline $\mathrm{X}_{\mathrm{NaCl}}=0.95$ & $1.03 \pm 0.02$ & $4.82 \pm 0.29$ \\
\hline $\mathrm{X}_{\mathrm{NaSal}}=0.33$ & $0.62 \pm 0.03$ & $3.56 \pm 0.15$ \\
\hline
\end{tabular}

\section{Thermodynamics of Micellization}

As we mentioned earlier, micellization in surfactant solution is sensitive to temperature and therefore thermodynamic parameters have been calculated by the temperature dependence of the $\mathrm{cmc}$ values (Figure 1). Two models are generally used to evaluate thermodynamic parameters; (1) phase separation model (pseudo-phase model) regards that micelles act as separate phase and assumes that monomer activity remains constant over the $\mathrm{cmc}$ and (2) mass action model (equilibrium model) regards micelle formation as an equilibrium condition in which the monomer activity continues to increase, although at a much reduced rate, above the cmc [40]. In our study, the phase separation model has been chosen to get thermodynamic energetics. For ionic gemini surfactants, the standard Gibbs free energy of micellization, $\Delta G_{\text {mic }}^{\circ}$, can be written as [7],

$\Delta G_{\text {mic }}^{\circ}=2 R T\left(1.5-\alpha_{\mathrm{a}}\right) \ln X_{\mathrm{cmc}}$

Where, $R, T$ and $X_{\mathrm{cmc}}$ are ideal gas constant, absolute temperature and $\mathrm{cmc}$ expressed in mole fraction unit, respectively.

The standard enthalpy change for micellization, $\Delta H_{\text {mic }}^{\circ}$, can be calculated by using Gibbs-Helmholtz eq 3 ,

$$
\Delta H_{\text {mic }}^{\circ}=-2 R T^{2}\left(1.5-\alpha_{\mathrm{a}}\right)\left(\partial \ln X_{\mathrm{cmc}} / \partial T\right)
$$



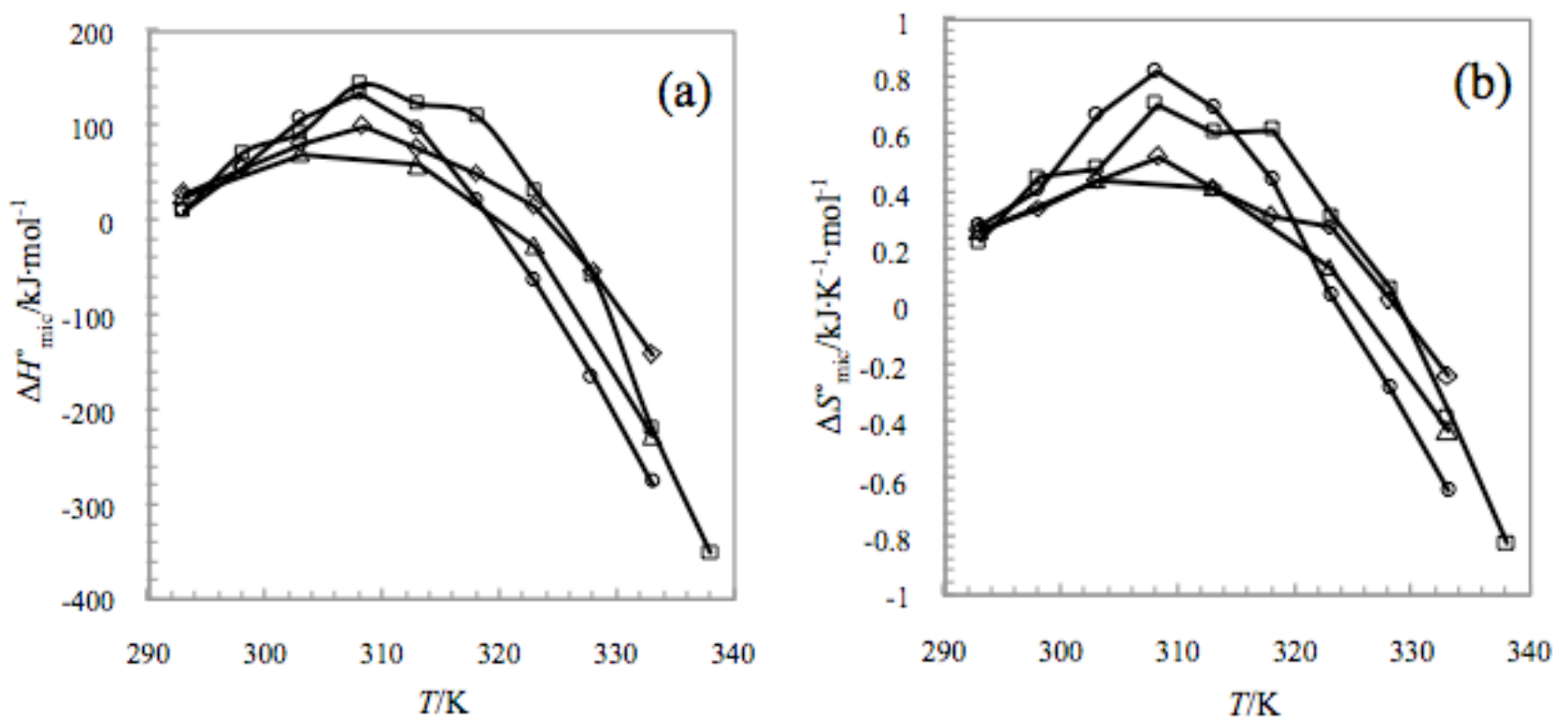

Figure 3: Thermodynamic Parameters (a) Standard Enthalpy $\left(\Delta H_{\text {mic }}^{\circ}\right)$ and (b) Standard Entropy $\left(\Delta S_{\text {mic }}^{\circ}\right)$ of Gemini Surfactant in; $\square$, Pure Water; $\diamond, \phi_{E G}=0.11 ; \Delta, x_{\mathrm{NaCl}}=0.95 ; \circ, x_{\mathrm{NaSal}}=0.33$.

Since, $\Delta H_{\text {mic }}^{\circ}$ is not constant with respect to temperature; the values were obtained by using following polynomial equation $[11,19]$

$\ln X_{\mathrm{cmc}}=\mathrm{a}+\mathrm{b} T+\mathrm{c} T^{2}+\mathrm{d} T^{3}$

On differentiating eq 4 , one can get the value of $\partial \ln X_{\mathrm{cmc}} / \partial T$ as,

$\partial \ln X_{\mathrm{cmc}} / \partial T=\mathrm{b}+2 \mathrm{c} T+3 \mathrm{~d} T^{2}$

The polynomial constants (a, b, c and d) are obtained by least square regression analyses. By substituting the value $\partial \ln X_{\mathrm{cmc}} / \partial T$ in to eq 3 , we get

$\Delta H_{\text {mic }}^{\circ}=-2 R T^{2}\left(1.5-\alpha_{\mathrm{a}}\right)\left(\mathrm{b}+2 \mathrm{c} T+3 \mathrm{~d} T^{2}\right)$

Finally, the standard entropy of the micellization, $\Delta S_{\text {mic }}^{\circ}$, evaluated from the values of $\Delta H_{\text {mic }}^{\circ}$ and $\Delta G_{\text {mic }}^{\circ}$ as follows,

$\Delta S_{\text {mic }}^{\circ}=\left(\Delta H_{\text {mic }}^{\circ}-\Delta G_{\text {mic }}^{\circ}\right) / T$

The results of $\Delta G_{\text {mic }}^{\circ}, \Delta H_{\text {mic }}^{\circ}$ and $\Delta S_{\text {mic }}^{\circ}$ obtained by the eqs 2,3 and 7 are also summarized in Tables 1 and 2 . The data show that the micellization process is endothermic at low temperature $\left(\Delta H_{\text {mic }}^{\circ}>0\right)$ and become exothermic at higher temperature $\left(\Delta H^{\circ}\right.$ mic $\left.<0\right)$. However, $\Delta G_{\text {mic }}^{\circ}<0$ which may be due to entropy effect, especially at low temperature. The value of negative enthalpy indicates that the London dispersion forces have a significant role in the micellization process at higher temperature. These forces are of predominant in nature and facilitating the micellization
[41]. The data of temperature dependence of $\Delta H^{\circ}$ mic and $\Delta S_{\text {mic }}^{\circ}$ are plotted in Figures 3.

In general, the compensation phenomenon between the $\Delta H^{\circ}$ mic and $\Delta S_{\text {mic }}$ in the micellization process can be described in the form of a straight line equation (see Figure 4) of the type

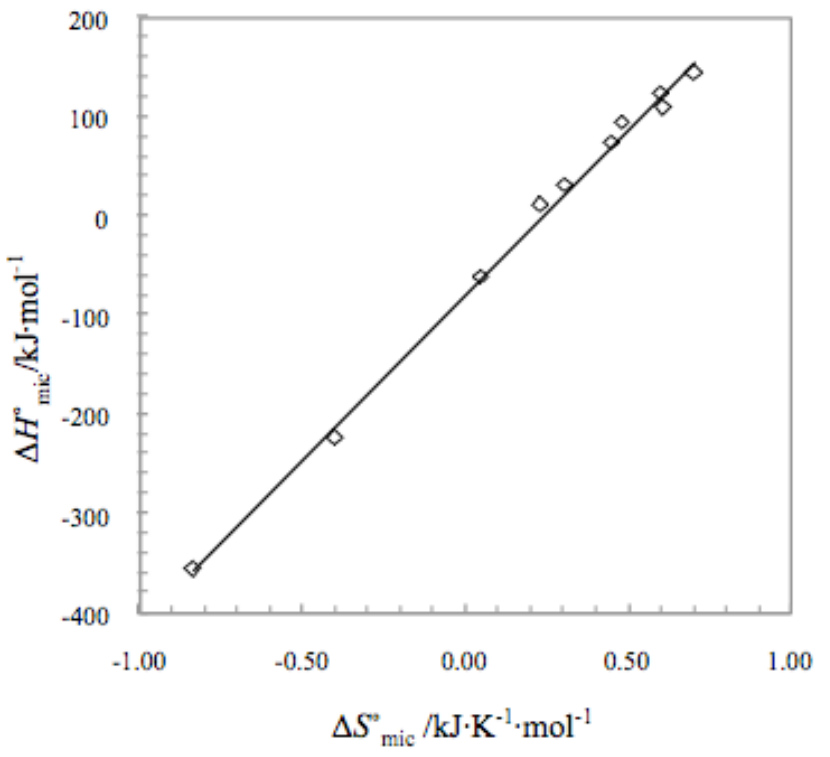

Figure 4: Plot of Standard Enthalpy $\left(\Delta H_{\text {mic }}^{\circ}\right)$ vs Standard Entropy $\left(\Delta S^{\circ}{ }_{\text {mic }}\right)$ of Gemini Surfactant in Pure Water.

$\Delta H_{\text {mic }}^{\circ}=T_{\mathrm{c}} \Delta S_{\text {mic }}^{\circ}+\Delta H_{\text {mic }}^{*}$

The slope is the compensation temperature $\left(T_{\mathrm{c}}\right)$ and is a characteristic of solute-solute and solute - solvent interaction. $T_{\mathrm{c}}$ can be considered as a measure of 
Table 5: Correlation Coefficient $(R)$, Compensation Temperature $\left(T_{\mathrm{C}}\right)$ and Intercept $\left(\Delta \boldsymbol{H}^{\star}{ }_{\mathrm{mic}}\right)$ of Gemini Surfactant in Different System and Compare with Literature Data

\begin{tabular}{|c|c|c|c|c|c|}
\hline \multirow{2}{*}{ Gemini surfactants } & \multirow{2}{*}{ Medium } & \multirow{2}{*}{$\mathbf{R}$} & $T_{\mathrm{c}}$ & $\Delta \boldsymbol{H}_{\text {mic }}^{*}$ & \multirow{2}{*}{ Ref. $^{c}$} \\
\hline & & & $\mathbf{K}$ & $\mathrm{kJ} \cdot \mathrm{mol}^{-1}$ & \\
\hline Gemini & Aqueous & 0.996 & $332 \pm 0.02$ & $-79.496 \pm 0.05$ & This work \\
\hline Gemini & $\phi_{\mathrm{EG}}=0.11$ & 0.990 & $327 \pm 0.04$ & $-62.858 \pm 0.06$ & This work \\
\hline Gemini & $x_{\mathrm{NaCl}}=0.95$ & 0.996 & $343 \pm 0.03$ & $-77.100 \pm 0.05$ & This work \\
\hline Gemini & $x_{\mathrm{NaSal}}=0.33$ & 0.990 & $283 \pm 0.04$ & $-86.258 \pm 0.07$ & This work \\
\hline $12-2-12$ & Aqueous & - & $293^{\mathrm{b}}$ & $-34.780^{b}$ & [29] \\
\hline $12-4-12$ & Aqueous & - & $290^{\mathrm{b}}$ & $-32.090^{b}$ & [29] \\
\hline $12-5-12$ & Aqueous & $0.999^{a}$ & $306^{b}$ & $-67.670^{\mathrm{a}}$ & [24] \\
\hline $14-2-14$ & Aqueous & - & $304^{b}$ & $-40.400^{b}$ & [29] \\
\hline $14-4-14$ & Aqueous & - & $296^{\mathrm{b}}$ & $-36.090^{b}$ & [29] \\
\hline $14-5-14$ & Aqueous & $0.976^{a}$ & $288^{\mathrm{b}}$ & $-73.350^{a}$ & {$[21]$} \\
\hline $14-5-14$ & $\phi_{E \mathrm{G}}=0.11$ & $0.995^{\mathrm{a}}$ & $310^{b}$ & $-73.396^{\mathrm{a}}$ & [21] \\
\hline $14-6-14$ & Aqueous & $0.972^{\mathrm{a}}$ & $204^{\mathrm{a}}$ & $-57.114^{a}$ & {$[5,22]$} \\
\hline
\end{tabular}

${ }^{a}$ Compensation temperature and intercept, Correlation Coefficient calculated by using thermodynamic parameters of respective reference.

${ }^{b}$ Data used as such given in the reference.

'Data obtained from conductance measurements.

desolvation part of the micellization (dehydration of the hydrocarbon tail). The intercept, $\Delta H_{\text {mic }}^{*}$, characterizes the solute -solute interaction and can be considered as an index of the chemical part of the micellization (aggregation of hydrocarbon tails in to the micelle). Compensation plots were drawn with each type of solvent (water, water $+\mathrm{EG}$, Water $+\mathrm{NaCl}$ or Water + $\mathrm{NaSal})$ but a representative plot is given for pure water (Figure 4). The $\Delta H_{\text {mic }}^{*}$ stands for the enthalpy effect when $\Delta S^{\circ}{ }_{\text {mic }}=0$. The decrease in $\Delta H_{\text {mic }}^{*}$ corresponds to micelle of higher stability. With $\mathrm{NaSal}$, the value of $\Delta H_{\text {mic }}^{*}$ is found much lower than the reported literature values (Table 5 ). In other words, the effect of chemical part of the process in micellization predominates in presence of the salt (especially for NaSal). The data in Table 5 suggest that $T_{\mathrm{c}}$ values in our systems are comparatively higher than the conventional gemini surfactants with polymethylene spacers. Further, $T_{\mathrm{c}}$ values are reported higher for non-ionic surfactants than their ionic counterparts [11]. This can be understood in the light of the fact that the hydration natures of the head groups are different in two classes of surfactant. It is interesting to note in our case that the $T_{\mathrm{c}}$ value matches with the values of non-ionic surfactants though gemini is ionic. This may be due to the presence of additional hydrophilicity in the spacer chain of the gemini surfactant to that of head group itself (Scheme 1).

\section{CONCLUSIONS}

The micellization behavior of gemini surfactant has been examined under various solvent conditions (water, $0.11 \phi_{\mathrm{EG}}, 0.95 x_{\mathrm{NaCl}}$ or $0.33 x_{\mathrm{NaSal}}$ ) at different temperatures. The $\mathrm{cmc}$ value decreases up to a certain value of temperature $\left(T_{\mathrm{m}}\right)$ for all the systems. However, the decrease was more pronounced with higher binding counterion ( $\mathrm{Sal}^{-}$). Temperature dependence of $\mathrm{cmc}$ can be fitted by a power law. The enthalpy of micellization $\left(\Delta H^{\circ}\right.$ mic $)$ passes through zero in all the systems which ascribed to the balance between enthalpy and entropy of the process coming from the hydrophobic effect. The compensation temperature, $T_{\mathrm{c}}$, was found similar to non-ionic surfactants which ascribes the higher hydration of the present cationic gemini surfactant. $\Delta H_{\text {mic }}^{*}$ values indicate that the micelle forms are more stable [11].

\section{ACKNOWLEDGEMENT}

The Authors are thankful to University Grants Commission, New Delhi, India for financial support (as a research grant) to carry out this work (F. No. 37$380 / 2009(\mathrm{SR})$ ). The use of research facilities provided by Head, Department of Chemistry, The Maharaja Sayajirao University of Baroda, is gratefully acknowledged. 


\section{APPENDIX}

$T_{\mathrm{m}} \quad=$ Temperature of minimum $\mathrm{cmc}$ (Temperature minima)

$\mathrm{cmc}_{\mathrm{m}}=\mathrm{cmc}$ at minimum temperature $(\mathrm{cmc}$ minima)

$T_{\mathrm{C}} \quad=\quad$ Compensation Temperature

$\mathrm{cmc}=$ Critical micelle concentration

$\alpha_{a} \quad=\quad$ Average degree of dissociation

$\Delta G_{\text {mic }}^{\circ}=$ Standard Gibbs free energy of micellization

$\Delta H_{\text {mic }}=$ Standard enthalpy of micellization

$\Delta S_{\text {mic }}=$ Standard entropy of micellization

$\phi_{E G}=$ mass fraction of ethylene glycol

$x_{\mathrm{NaCl}}=$ mole fraction of sodium chloride

$x_{\text {NaSal }}=$ mole fraction of sodium salicylate

\section{REFERENCES}

[1] Kim HJ, Kim T, Lee M. Responsive nanostructures from aqueous assembly of rigid-flexible block molecules. Acc Chem Res 2011; 44: 72-82. http://dx.doi.org/10.1021/ar100111n

Kabir-ud-Din, Siddiqui US, Kumar S, Dar AA. Micellization of monomeric and dimeric (gemini) surfactants in polar nonaqueous-water-mixed solvents. Coll Polym Sci 2006; 284: 807-12.

http://dx.doi.org/10.1007/s00396-005-1449-4

[3] Kumar S, Parveen N, Kabir-ud-Din. Effect of urea addition on micellization and related phenomena. J Phys Chem B 2004; 108: 9588-92.

http://dx.doi.org/10.1021/jp036552w

[4] Mitra D, Chakraborty I, Bhattacharya SC, Moulik SP. Interfacial and solution properties of tetra alkyl ammonium bromides and their sodium dodecyl sulfate interacted products: a detailed physicochemical study. Langmuir 2007; 23: 3049-61.

http://dx.doi.org/10.1021/la062830h

[5] Kabir-ud-Din, Koya PA. Micellar properties and related thermodynamic parameters of the 14-6-14, $2 \mathrm{Br}^{-}$gemini surfactant in water + organic solvent mixed media. J Chem Eng Data 2010; 55: 1921-9.

http://dx.doi.org/10.1021/je900894x

[6] Menger FM, Keiper JS. Gemini surfactants. Angew Chem Int Ed 2000; 39: 1906-20.

[7] Zana R. Dimeric and oligomeric surfactants. behavior at interfaces and in aqueous solution: a review. Adv Coll Interface Sci 2002; 97: 205-53. http://dx.doi.org/10.1016/S0001-8686(01)00069-0

[8] Borse M, Sharma V, Aswal VK, Goyal PS, Devi S. Effect of head group polarity and spacer chain length on the aggregation properties of gemini surfactants in an aquatic environment. J Coll Interface Sci 2005; 284: 282-8. http://dx.doi.org/10.1016/j.jcis.2004.10.008
[9]

Laatiris A, El Achouri $M$, Infante MR, Bensouda $Y$ Antibacterial activity, structure and $\mathrm{cmc}$ relationship of alkanediyl $\alpha, \omega$-bis(dimethylammonium bromide) surfactants. Microbiol Res 2008; 163: 645-50.

http://dx.doi.org/10.1016/j.micres.2006.09.006

[10] La Mesa C. Dependence of critical micelle concentrations on intensive variables: a reduced variables analysis. J Phys Chem 1990; 94: 323-6. http://dx.doi.org/10.1021/j100364a054

[11] Chen L-J, Lin S-Y, Huang C-C. Effect of hydrophobic chain length of surfactants on enthalpy - entropy compensation of micellization. J Phys Chem B 1998; 102: 4350-6. http://dx.doi.org/10.1021/jp9804345

[12] Gonzalez-Perez A, Del Castillo JL, Czapkiewicz J, Rodriguez JR. Conductivity, density and adiabatic compressibility of dodecyl dimethyl benzyl ammonium chloride in aqueous solutions. J Phys Chem B 2001; 105: 1720-4. http://dx.doi.org/10.1021/jp0022149

[13] Perger T-M, Bester-Rogac M. Thermodynamics of micelle formation of alkyl trimethyl ammonium chlorides from high performance electric conductivity measurements. J Coll Interface Sci 2007; 313: 288-95. http://dx.doi.org/10.1016/.j.jcis.2007.04.043

[14] Pahi AB, Varga D, Kiraly Z, Mastalir A. Thermodynamics of micelle formation of the ephedrine-based chiral cationic surfactant DMEB in water, and the intercalation of DMEB in montmorillonite. Coll Surf A: Physicochem Eng Aspects 2008; 319: 77-83.

http://dx.doi.org/10.1016/i.colsurfa.2007.06.056

[15] Stasiuk ENB, Schramm LL. The temperature dependence of critical micelle concentrations of foam-forming surfactants. $J$ Coll Interface Sci 1996; 178: 324-33.

http://dx.doi.org/10.1006/jcis.1996.0120

[16] Sarac B, Bester-Rogac M. Temperature and salt-induced micellization of dodecyl trimethyl ammonium chloride in aqueous solution: a thermodynamic study. J Coll Interface Sci 2009; 338: 216-21.

http://dx.doi.org/10.1016/j.jcis.2009.06.027

[17] Bai G, Wang J, Yan H, Li Z, Thomas RK. Thermodynamics of molecular self-assembly of cationic gemini and related double chain surfactants in aqueous solution. J Phys Chem B 2001; 105: 3105-8. http://dx.doi.org/10.1021/jp0043017

[18] Zhaoxi ZY, Ou Z, Yi Y, Yu Q. Temperature dependence and enthalpy-entropy compensation micellization of gemin surfactants in aqueous solutions. Acta Chim Sin 2001; 59: 690-5.

[19] Bakshi MS, Kaura A, Mahajan RK. Effects of temperature on the micellar properties of polyoxyethylene chain glycol and twin tail alkyl ammonium surfactants. Coll Surf A: Physicochem Eng Aspects 2005; 262: 168-74.

http://dx.doi.org/10.1016/j.colsurfa.2005.04.027

[20] Pahi AB, Kitaly Z, Mastalir A, Dudas J, Puskas S, Vago A. Thermodynamics of micelle formation of the counterion coupled gemini surfactant bis(4-92dodecyl)benzenesulfonate)-jeffamine salt and its dynamic adsorption on sandstone. J Phys Chem B 2008; 112: 153206. http://dx.doi.org/10.1021/jp806522h

[21] Kabir-ud-Din, Koya PA, Khan ZA. Conductometric studies of micellization of gemini surfactant pentamethylene-1,5bis(tetradeyl dimethyl ammonium bromide) in water-organic solvent mixed media. J Coll Interface Sci 2010; 342: 340-7. http://dx.doi.org/10.1016/j.jcis.2009.10.056

[22] Kabir-ud-Din, Koya PA. Effects of solvent media and temperature on the self-aggregation of cationic dimeric surfactant $14-6-14,2 \mathrm{br}^{-}$studied by conductometric and fluorescence techniques. Langmuir 2010; 26: 7905-14. 
[23] Kabir-ud-Din, Koya PA, Khan ZA. Studies on the effect of organic solvents and temperature on the micellar solution of pentamethylene-1,5-bis(tetradecyldimethylammonium bromide) gemini surfactant. J Dispersion Sci Technol 2011; 32: $558-67$ http://dx.doi.org/10.1080/01932691003757256

[24] Yan Z, Li Y, Wang X, Dan J, Wang J. Effect of glycyl dipeptides on the micellar-behaviour of gemini surfactant: a conductometric and fluorescence spectroscopy study. J Mol Liquid 2011; 161: 49-54. http://dx.doi.org/10.1016/j.molliq.2011.04.009

[25] Liu G, Gu D, Liu H, Ding W, Li Z. Enthalpy - entropy compensation of ionic -type gemini imidazolium surfactants in aqueous solution: a free energy perturbation study. J Coll Interface Sci 2011; 358: 521-6. http://dx.doi.org/10.1016/.j.jcis.2011.03.064

[26] Chavda S, Kuperkar K, Bhadur P. Formation and growth of gemini surfactant (12-s-12) micelles as a modulate by spacers: a thermodynamic and small-angle neutron scattering (sans) study. J Chem Eng Data 2011; 56: 264754. http://dx.doi.org/10.1021/je2001683

[27] Zarganian $R$, Bordbar AK, Amiri R, Tamannaei $M$, Khosropour AR, Mohammdapoor-Baltork I. Micellization of pentanediyl-1,5-bis(hydroxy ethyl methyl hexadecyl ammonium bromide as a cationic gemini surfactant in aqueous solutions: investigation using conductometry and fluorescence techniques. J Solution Chem 2011; 40: 921-8. http://dx.doi.org/10.1007/s10953-011-9694-2

[28] Batigoc C, Akbas H, Boz M. Micellization behavior and thermodynamics parameters of 12-2-12 gemini surfactant in (water + organic solvent) mixtures. J Chem Thermodyn 2011; 43: $1349-54$

http://dx.doi.org/10.1016/j.jct.2011.04.007

[29] Alimohammadi MH, Javadian S, Gharibi H, Tehrani-Bhagha AR, Alavijeh MR, Kakaei K. Aggregation behavior and intermicellar interactions of cationic gemini surfactants: effect of alkyl chain, spacer lengths and temperature. J Chem Thermodyn 2012; 44: 107-15. http://dx.doi.org/10.1016/j.jct.2011.08.007

[30] Wetting SD, Li X, Verral RE. Thermodynamic and aggregation properties of gemini surfactants with ethoxylated spacers in a aqueous solution. Langmuir 2003; 19: 3666-70. http://dx.doi.org/10.1021/la0340100

[31] Bai G, Yan H, Thomas RK. Microcalorimetric studies on the thermodynamic properties of cationic gemini surfactants. Langmuir 2001; 17: 4501-4. http://dx.doi.org/10.1021/la001472u
[32] Hellberg P-E, Bergstrom K, Holmberg K. Cleavable surfactants. J Surfact Detergent 2000; 3: 81-91. http://dx.doi.org/10.1007/s11743-000-0118-z

[33] Baixia L, Yuquan L, Yinkui L. Synthesis of alphachloroacetates of ethylene glycol and its oligomers. Acta Polym Sin 1992; 2: 34-41.

[34] Zhinong G, Shuxin T, Qi Z, et al. Synhesis and surface activity of biquarternary ammonium salt gemini surfactants with ester bond. Wuhan Univ J Nat Sci 2008; 13: 227-31. http://dx.doi.org/10.1007/s11859-008-0219-9

[35] Rosen MJ. Surfactants and Interfacial Phenomena. 3rd ed. John Wiley \& Sons: New Jersey 2004. http://dx.doi.org/10.1002/0471670561

[36] Sarkar B, Lam S, Alexandridis P. Micellization of alkylpropoxy-ethoxylate surfactants in water-polar organic solvent mixtures. Langmuir 2010; 26: 10532-40. http://dx.doi.org/10.1021/la100544w

[37] Chakraborty I, Moulik SP. Self-aggregation of ionic $C(10)$ surfactants having different head groups with special reference to the behavior of decyltrimethyl ammonium bromide in different salt environments: a calorimetric study with energetic analysis. J Phys Chem B 2007; 111: 3658-64. http://dx.doi.org/10.1021/jp066500h

[38] Rehage $H$, Hoffmann $H$. Rheological properties of viscoelastic surfactant systems. J Phys Chem 1988; 92: 4712-19.

http://dx.doi.org/10.1021/j100327a031

[39] Kang KH, Kim HU, Lim KH. Effect of temperature on critical micelle concentration and thermodynamic potentials of micellization of anionic ammonium dodecyl sulfate and cationic octadecyl trimethyl ammonium chloride. Coll Surf A: Physicochem Eng Aspects 2001; 189: 113-21. http://dx.doi.org/10.1016/S0927-7757(01)00577-5

[40] Swarbrick J, Daruwala J. Thermodynamics of micellization of some zwitterionic n-alkyl betaines. J Phys Chem 1969; 73 2627-32.

http://dx.doi.org/10.1021/j100842a029

[41] Del Rio JM, Pombo C, Prieto G, Mosquera V, Sarmiento F. Effect of temperature and alkyl chain length on the micellization properties of n-alkyltrimethyl ammonium bromides in a low ph medium. J Coll Interface Sci 1995; 172: 137-41. http://dx.doi.org/10.1006/jcis.1995.1235 